\title{
A Psycholinguistic Study of Metaphor Processing
}

\author{
Xiu Yu \\ Qingdao University of Science \& Technology Qingdao, China \\ Email: yuxiu66@yahoo.com.cn
}

\begin{abstract}
This paper aims to present some issues about metaphor comprehension process mainly from psycholinguistic point of view. By discussing these issues, more information about the nature of metaphor comprehension can be learnt.
\end{abstract}

Index Terms-metaphor comprehension process, context, the "quality" of metaphors, conceptual metaphor, class inclusion

\section{INTRODUCTION}

Metaphor in one form or another is absolutely fundamental to the way language systems develop over time, as well as to the way human beings consolidate and extend their ideas about knowledge of the world. Since metaphor is used all the time, it has been widely studied in literature and has been examined in a number of areas of linguistics.

This paper mainly explores some aspects of metaphor comprehension process from psycholinguistic perspective.

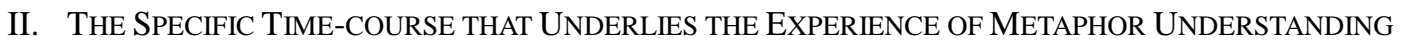

Literary theories and philosophers mainly focus on metaphor understanding as a product and try to infer something about the process of metaphor comprehension. Psycholinguistics or psychologists, on the other hand, primarily study comprehension processes with an eye towards explicating something about the products of metaphor interpretation and recognition (i.e. what metaphors mean).

In order to know more about metaphor comprehension, we can first recognize the specific time-course that underlies the experience of metaphor understanding. One way of doing this is to realize that the temporal continuum of linguistic understanding may roughly be divided into moments corresponding to linguistic comprehension, recognition, interpretation and appreciation. Consider each of these in turn (Gibbs, 2001):

Comprehension refers to the immediate, moment-by-moment process of creating meanings for utterances. These moment-by-moment processes are generally unconscious and include the analysis of different linguistic information which, in combination with context and the real-world knowledge, allow people to figure out what, say, a metaphor means or what a person intends by his or her reading of a metaphorical expression. Recent psycholinguistic research shows that this processes operate very quickly, that is, within the time span of a few hundred milliseconds up to a few seconds at most.

Recognition refers to the conscious identification of the products of comprehension as types. For example, the meaning understood by a reader of a particular utterance may be consciously recognized as being metaphorical. Even though many literary theorists assume that such a recognition is a requirement for understanding what an utterance or text means, it is by no means clear that recognition is an obligatory stage in people's understanding of what utterances mean, or of what speakers/authors intend. Listeners, for instance, probably do not have any conscious recognition that different utterances are idiomatic, literal and so on. Instead, they concentrate mainly on understanding what people intend to communicate by their production of metaphor.

Interpretation refers to analysis of the early products comprehension as tokens. A person can consciously create an understanding for a particular meaning. Generally, interpretation processes operate at a later point in time than comprehension processes.

At last, appreciation refers to some aesthetic judgment given to a product either as a type or token. This is not a necessary part of metaphor understanding. According to the psychological evidence, metaphor comprehension and appreciation refer to distinct types of mental process.

\section{DifFerent Views on the Relationship Between Literal MeAning Processing AND METAPHOR Processing}

Within psycholinguistics, the main topic of investigation has once been whether metaphorical comprehension is "indirect" or "direct".

\section{A. The "Indirect" View}

There is a prevalent view in psycholinguistics that the processing of indirect speech acts, such as metaphor, is a three-stage process involving: (1) Assessment of the most "literal" meaning; (2) Comparison of literal meaning to a communication context; (3) Deciding conflicts between literal meaning and context (Rice, 1999). 
Metaphor, according to this view, has been explained as a secondary linguistic process which takes place as a function taking place on literal language. In other words, all utterances would be processed as literal utterances first. Only once the mind was unable to find a literal meaning for an expression would the utterance be sent to a special non-literal processing center for decoding. It necessarily entails that the comprehension of a metaphor assumes the metaphorical expression will eventually be decomposed into a literal paraphrase (Rohrer, 1995). Therefore, the hearer seeks a metaphorical interpretation only after the search for a plausible literal meaning fails.

\section{B. The "Direct" View}

However, the "indirect" explanation does not fit well with some of the recent cognitive studies or recent work on right hemisphere processing of language, both of which suggest that the figurative and literal language are processed simultaneously and share much structure (Rohrer 1995). An influential piece of early research by Glucksberg and his colleagues dealt a conclusive blow to the "indirect" view. Their studies provided strong evidence against the view that people attempt a literal interpretation firstly and then resort to metaphorical interpretation only if the literal interpretation is anomalous. Participants were simply asked to make true or false judgments. The materials included true category statements (e.g. 'Some birds are robins'), false category statements (e.g. 'Some birds are apples'), and metaphorical statements (e.g. 'Some jobs are jails'). Note that the answer is 'true' only for the first class; the other two are 'false'. The key question concerned how people would process the metaphors. According to the "indirect" theory, people should have been fast to reject metaphors; they simply had to press 'false' as soon as they realized that the literal meaning was false. However, the results showed the reverse. Participants took much longer to reject metaphors than ordinary false statements, suggesting that the metaphorical meaning was noticed early and interfered with participants' ability to classify it as false (Dedre Gentner, Brian Bowdle. 2006).

Some recent study suggests that people understand metaphors much the same way they understand the literal speech - by retrieving information from the lexicon, selecting the part that is germane, and identifying a relationship between the lexical representations that have been retrieved (Carroll, 2000).

To sum up, it has been proposed that metaphors are primarily used to convey ideas and feelings that are difficult to express. People comprehend metaphor by a multistage process in which they first consider and reject the literal meaning and then to construct the speaker's intended meaning. However, recent study on metaphors fails to support this view. On the contrary, people always tend to comprehend metaphors directly, in a manner analogous to, rather than dependent on literal language (Carroll, 2000).

\section{MAIN FACTORS THAT InFLUENCE THE PROCESSING TIME OF METAPHOR}

\section{A. Context}

In general, the surrounding context of utterance can influence metaphor comprehension time. It turns out that when more context is available (in the experience of the listener) then the measured interpretation time for metaphor is about the same as for literal speech acts. In any case, certain "schemata" in the available "context" are assumed to be "activated." This explanation suggests that when insufficient schemata are activated by the context then the listener has to scratch around for other schemata that may be "semantically more remote", thus requiring more time to access (Carroll, 2000).

Ortony, Schallert, Reynolds \& Antos (1978) once measured the time it took subjects to comprehend literal v. metaphorical sentences at the end of short and long contexts, and reported no difference for long contexts but that metaphorical sentences took much longer to read in short contexts. Janus \& Bever (1985) tracked eye movements and compared the amount of time subjects focused on the target sentences. People again responded as quickly in the long context condition. Therefore, context is seen as at least the major key to metaphor processing. If it is adequate, then metaphors are processed as fast as literal language (Rice, 1999).

\section{B. The "Quality" of Metaphors}

In the study of metaphor processing, the "quality" of metaphors is acknowledged to be a problem. A crude distinction is made between "poorer" and "better metaphors" ones. The poorer ones supplying relevance only to a few interpretations while the better ones apply to more situations. This, however, implies that novel metaphors, having more difficult or restricted interpretations, are poorer, and that familiar metaphors are the better ones. Poorer metaphors interfere less with sentence comprehension, presumably because they are taken less seriously. If we say, "All surgeons are butchers" it is perhaps a poor metaphor in this sense. We do not expect surgeons to be filed under butchers in a relational database of job categories, or expect surgeons' friends to think it is a wonderful trope (Rice, 1999).

According to Lakoff and Johnson, new metaphors, or novel metaphors, are different from conventional metaphors in that they are beyond social conventions and "are capable of giving us a new understanding of our experience" (Lakoff and Johnson, 1980:139). The power of new metaphors is to create a new reality rather than simply to give mankind a way of conceptualizing a preexisting reality as conventional metaphors do (Lakoff and Johnson, 1980). Therefore, new metaphors play a very important role in imagination and creation of new meaning.

New metaphors use the mechanisms of conventional and everyday thought in extraordinary ways. That is, what makes the new metaphors noticeable and memorable is that new metaphors extend them, elaborate them, and combine 
them in ways that go beyond the bounds of ordinary modes of thought and beyond the automatic and unconscious conventional use of metaphor ( Lakoff and Turner, 1989). So to speak, the study of new metaphor is an extension of the study of conventional metaphor. Conventional metaphor is characterized by a huge system of cross domain mappings, and this system is made use of in new metaphor.

For example, the conventional metaphor DEATH IS SLEEP, is a general and ordinary metaphorical conception that views death as sleeping when people speak of someone that passed away. The mapping in this metaphor, of course, does not involve all people's general knowledge about death, but only certain aspects: inactive, inattentive and so on. However, in Hamlet's soliloquy, Shakespeare extends creatively the ordinary metaphor of death as sleeping to include elements that are not conventionally mapped--the possibility of dreaming (Lakoff and Turner, 1989):

To sleep? Perchance to dream! Ay, there's the rub;

For in that sleep of death what dreams may come?

(William Shakespeare, Hamlet, Prince of Denmark, Act III, Scene I)

Various studies (e.g. Blasko and Connine 1993) have found that unfamiliar and novel metaphors take significantly longer to process than either literal sentences or familiar metaphors.

\section{Two DIFFERENT SCHOOLS OF THOUGHT ON PROCESSING OF METAPHORICAL EXPRESSIONS}

Generally, there are two schools of thought that regarding the cognitive processing of metaphorical expressions. One is advocated by Gibbs (1994) whose research affirms and extends the proposals of Lakoff and Johnson, and Glucksberg (2001) who proposes an alternative view of metaphor processing based on his and his colleagues' experimental results.

In Metaphors We Live By, Lakoff and Johnson (1980) state that human conceptual system is metaphorically structured and defined. According to them, conceptual metaphor is a system of metaphor that lies behind much of everyday language and forms everyday conceptual system, including most abstract concepts. Metaphor, in essence, is "understanding and experiencing one kind of thing in terms of another" (Lakoff and Johnson, 1980: 5). According to Lakoff and Johnson (1980), the working mechanism of conceptual metaphors lies in the fact that conceptual metaphors are mappings across different conceptual domains, involving projections from a source domain to a target domain. They claim that:

a. Metaphorical mapping is uni-directional and asymmetric, that is, from the more concrete to the more abstract.

b. Metaphorical mapping is partial, not total, namely, the structure of the source domain is only partly projected to the structure of the target domain.

c. Metaphorical mapping is not random and arbitrary, but grounded in the body and everyday experience in the physical and cultural world.

d. Metaphorical mapping is systematic across different conceptual domains.

Along with Lakoff and Johnson, Gibbs claims that long-term memory is structurally organized by prototypes extended by metaphoric and metonymic principles called conceptual mappings or conceptual metaphors. A conceptual metaphor, such as LOVE IS A JOURNEY, is constituted by a mapping between areas of the brain, such as between affect and sensorimotor areas. In the appropriate context, most conventional metaphoric expressions, such as our marriage is on the rocks or we're at a crossroads, access these conceptual metaphors from long-term memory (Rohrer, 1995).

Glucksberg, Keysar and McGlone (1990) argue for a class inclusion view in which some metaphoric expressions build up an ad-hoc category in working memory rather than accessing conceptual metaphors from long-term memory, even when it would be expected that they would draw on a conceptual metaphor. In terms of this, Gibbs argues that the class-inclusion view needs an understanding of metaphor in which each metaphorical expression creates a unique or novel mapping in working memory. In their reply Glucksberg, Keysar and McGlone suggest that only some cases require the development of ad-hoc category, citing a brief initial experiment in which subjects were given metaphorical with minimal context and asked to paraphrase them (Rohrer, 1995).

\section{CONCLUSION}

Metaphor, like all figurative language, has been usually explained as a secondary linguistic process which takes place as a function taking place on literal language. However, recent study suggests that people understand metaphors much the same way they understand the literal speech. Context and the "quality" of metaphors can influence the processing time of metaphors. As to the cognitive processing of metaphorical expressions, different schools of thought hold different opinions. In fact, we should note that both perspectives are essential for us to learn metaphor process.

\section{REFERENCES}

[1] Blasko, D., \& Connine, C. (1993). Effects of familiarity and aptness on metaphor processing. Journal of Experimental Psychology: Learning Memory, and Cognition, 19, 295-308.

[2] Carroll, D. W. (2000). Psychology of Language. Beijing: Foreign Language Teaching and Research Press.
[3] Gentner,
D. and Bowdle,
B. (2006).
(2006). Web
Transcription
Tool. http://onlinelibrary.wiley.com/doi/10.1002/0470018860.s00579/full (accessed 6/5/2006). 
[4] Gibbs, R. W. (1994). The Poetics of Mind: Figurative Thought, Language and Understanding. Cambridge, Eng.: Cambridge University Press.

[5] Gibbs, R. W. (2001). Researching metaphor. In L. Cameron \& G. Low (Eds.), Researching and applying metaphor. Shanghai: Shanghai Foreign Language Education Press.

[6] Glucksberg, S. (2001). Understanding Figurative Language: from Metaphors to Idioms. Oxford: Oxford University Press.

[7] Glucksberg, Sam, B. Keysar \& M. McGlone. (1990). Metaphor understanding and accessing conceptual schema: Reply to Gibbs (1992). Psychological Review, 99, 578-581.

[8] Janus, R., \& Bever, T. (1985). Processing metaphoric language: An investigation of the three stage model of metaphor comprehension. Journal of Psycholinguistic Research, 14, 473-487.

[9] Lakoff, G. and Johnson, M. (1980). Metaphors We Live By. Chicago and London: University of Chicago Press.

[10] Lakoff, G. and Turner, M. (1989). More than Cool Reason: A Field Guide to Poetic Metaphor. Chicago: University of Chicago Press.

[11] Ortony, Andrew, D. Schallert, R. Reynolds \& S. Antos. (1978). Interpreting metaphors and idioms: Some effects of context on comprehension. Journal of Verbal Learning and Verbal Behavior, 17, 465-477.

[12] Stan Rice. (1999). Web Transcription Tool. http://www.cruzio.com/ autospec/ (accessed 7/5/2006).

[13] Rohrer, Tim. (1995). Web Transcription Tool. http://www.uoregon/metaphor (accessed 8/5/2006).

Xiu Yu was born in Qingdao, China in 1980. She received her M.A. degree in linguistics from Ocean University of China, China in 2007.

She is currently a teacher in the School of Foreign Languages, Qingdao University of Science \& Technology, Qingdao, China. Her research interests include psycholinguistics and cognitive linguistics.

Miss $\mathrm{Yu}$ is a member of the linguistic research center in the School of Foreign Languages, Qingdao University of Science \& Technology. 